\title{
Velopharyngeal dysfunction: a systematic review of major instrumental and auditory-perceptual assessments
}

\author{
Lauren Medeiros Paniagua', Alana Verza Signorini', Sady Selaimen da Costa ${ }^{3}$, Marcus Vinicius Martins Collares ${ }^{4}$, \\ Sílvia Dornelles 5 .
}

1) Speech Language Pathologist. Doctor of Science in Children's and Teenager's Health- Universidade Federal do Rio Grande do Sul-UFRGS. Professor of Speech-Language Pathology at Fatima College (RS).

2) Undergraduate Speech Pathology Fellow - Universidade Federal do Rio Grande do Sul - UFRGS. Undergraduate fellow of CNPq

3) MD; MSc; PhD. Associate Professor - Department of Otolaryngology \& Head and Neck Surgery/School of Medicine Universidade Federal do Rio Grande do Sul.

4) MD; PhD. Associate Professor - Department of Surgery; Head, Plastic Surgery Section - School of Medicine/Universidade Federal do Rio Grande do Sul.

5) Speech Pathology, MSc, PhD. Professor - Department of Speech Pathology/ Universidade Federal do Rio Grande do Sul.

Institution: Universidade Federal do Rio Grande do Sul (UFRGS)

Porto Alegre / RS - Brazil.

Mailing address: Lauren Medeiros Paniagua - Universidade Federal do Rio Grande do Sul (UFRGS) - Avenida João Wallig $1705 / 627$ - Porto Alegre / RS - Brazil - Zip Code 91340-001 - E-mail: lmedeirospaniagua@yahoo.com.br

Article received on December $2^{\text {nd }}, 2012$. Article accepted on April 15 $5^{\text {th }}, 2013$.

\section{SUMMARY}

Introduction: Velopharyngeal dysfunction may cause impaired verbal communication skills in individuals with cleft lip and palate; thus, patients with this disorder need to undergo both instrumental and auditory-perceptual assessments.

Objective: To investigate the main methods used to evaluate velopharyngeal function in individuals with cleft lip and palate and to determine whether there is an association between videonasoendoscopy results and auditory-perceptual assessments. Method: We conducted a systematic review of the literature on instrumental and auditory-perceptual assessments. We searched the PubMed, Medline, Lilacs, Cochrane, and SciELO databases from October to November 2012.

Summary of findings: We found 1,300 studies about the topic of interest published between 1990 and 2012 . Of these, 56 studies focused on velopharyngeal physiology; 29 studies presented data on velopharyngeal physiology using at least 1 instrumental assessment and/or 1 auditory-perceptual assessment, and 12 studies associated the results of both types of assessments. Only 3 studies described in detail the analysis of both methods of evaluating velopharyngeal function; however, associations between these findings were not analyzed.

Conclusion: We found few studies clearly addressing the criteria chosen to investigate velopharyngeal dysfunction and associations between videonasoendoscopy results and auditory-perceptual assessments.

Keywords: Cleft Palate; Communication Disorders; Velopharyngeal Sphincter

\section{INTRODUCTION}

The velopharyngeal mechanism relies on the action of the velopharyngeal sphincter to control the distribution of voiced and voiceless airstream in both the oral cavity and the nasal cavity. Individuals with an impaired velopharyngeal mechanism will develop velopharyngeal dysfunction (VPD), which may compromise the verbal communication skills of patients with an intact velopharyngeal sphincter (VPS). One of the consequences of such dysfunction is hypernasality, which has a great impact on the individuals with this condition.

Hypernasality induces nasal resonance in sounds that should not have this characteristic in articulate speech. This is caused by excessive nasal air emissions and weak intraoral pressure for some sounds. Nasal air escape and hypernasality are typical of VPD. Hypernasality is a resonance alteration that affects the emission of vowel sounds, whereas nasal air escape is a change in speech articulation that hinders the production of high pressure consonants such as plosives and fricatives (1).

Several methods for evaluating the VPS have been designed. The choice of a specific evaluation method is directly related to the focus of interest of a clinical investigation and its need for accuracy. The use of 1 auditory-perceptual assessment and at least 1 instrumental assessment is recommended for the analysis of velopharyngeal function $(2,3)$.

Auditory-perceptual assessment is the main method for detecting possible changes in speech nasality, and provides data on the function of velopharyngeal structures during speech production. That is, this evaluation method makes it possible to detect specific symptoms of cleft palate that may or may not be associated with VPD (4, 5 , $6,7)$. Because auditory-perceptual assessment is easily performed, it is the most commonly used evaluation 
method in clinical practice $(8,9)$. Analysis of the test results has been widely discussed in the literature because of a lack of uniformity in the protocols used by researchers and institutions, which makes it difficult to compare study results (2).

Videonasoendoscopy shows dynamic, direct, and natural images of the anatomical structures of the nasal cavity, pharynx, and larynx; this imaging method is thus one of the most appropriate tools for assessment of the VPS (10). Velopharyngeal closure patterns and the presence of a velopharyngeal gap (i.e., a residual opening during maximum contraction of the VPS) can be detected during performance of the test. Such patterns can also be identified during speech production, including the characteristics and degree of movement of the soft palate and pharyngeal walls $(11,12,13)$.

Based on both the literature and clinical practice, it is possible to state that the anatomy and physiology of the velopharyngeal mechanism are complex. Velopharyngeal dysfunctions that impair oral communication skills because of hypernasality, nasal air escape, and other disorders can be detected in individuals with cleft lip and palate. Therefore, the objective of the present review was to investigate the main methods used to evaluate the velopharyngeal function in individuals with cleft lip and palate, and to determine whether there is an association between videonasoendoscopy results and auditory-perceptual assessments.

\section{METHOD}

A systematic review of the literature is aimed at providing answers to specific questions and is based on clear and systematic methods in order to identify, select, and critically evaluate studies that may meet the proposed objective $(14,15)$. In order to perform the present systematic review of the literature, we searched studies conducted in different countries addressing the types of assessments used to describe the velopharyngeal function in individuals with surgically repaired cleft lip and palate. The following research questions were proposed: What are the main methods of velopharyngeal function assessment used in individuals with cleft lip and palate and how are the findings analyzed by the examiner? Is there an association between videonasoendoscopy results and auditoryperceptual assessments?

We searched the PubMed, Medline, Lilacs, Cochrane, and SciELO databases from October to November 2012. The same search strategy was used for all databases. Our search strategy included only manuscripts published between 1990 and 2012. This period was selected based on the fact that videonasoendoscopy first appeared in the literature in 1990. First, we selected the keywords to search the databases considering our research questions. The following keywords were used alone and in combination with the other terms: "cleft palate," "velopharyngeal closure," "velopharyngeal insufficiency," "velopharyngeal dysfunction," "compensatory articulation," "videonasoendoscopy," "assessment and hypernasality," "velopharyngeal mechanism," "hypernasality," and "speech."

The abstracts and titles of the manuscripts were selected by 2 researchers who worked independently. A reviewer resolved potential discrepancies of opinion. The full text of all potentially relevant manuscripts was obtained and analyzed separately by 2 reviewers based on the following inclusion criteria: (1) involved adults or children with cleft lip and palate; (2) included at least 1 videonasoendoscopy and 1 auditory-perceptual assessment for screening of VPD; (3) described the methods and criteria used for the analysis of the velopharyngeal functional assessment results. Studies on cleft lip and palate focused on audiological findings, classification of different cleft types, and surgical interventions were excluded. Finally, 2 researchers who specialize in the area of interest in the present study revised the selection of manuscripts with the purpose of refining the results.

\section{RESULTS AND DISCUSSION}

Considering the objective of the present review of the literature, our search of the previously mentioned scientific databases retrieved 1,300 manuscripts on velopharyngeal dysfunction in individuals with cleft lip and palate. Of these, 56 studies addressing velopharyngeal physiology were selected. Among these studies, there were 29 studies including data about auditory-perceptual assessment, some of which were associated with other instrumental assessments. We selected 12 studies that found an association between instrumental assessments (videonasoendoscopy and other tests) and auditoryperceptual assessment. Of these, 6 studies used videonasoendoscopy and auditory-perceptual assessment to evaluate velopharyngeal function. We refined our search in accordance with the objective of the present review and found only 3 studies that included an explanatory description of the analysis of both types of assessments.

The characteristics of each study included in this review are shown in Table 1 . The 12 studies selected were conducted in 4 different countries, including Brazil. These studies involved patients with different types of cleft lip and palate, including submucous cleft. Their age ranged from 3 to 76 years (Table 1). 
Table I. Characteristics of the study.

\begin{tabular}{llll}
\hline Author & Country & Type of cleft & Age group \\
\hline Araújo Netto \& Cervantes, 20II & Brazil & CLP, CP & $4-19$ years old \\
Trindade etal., 2004 & Brazil & CLP, SCP & NA \\
Chanchareonsooketal., 2007 & China & CP & I2-18 years old \\
Kao etal., 2008 & UnitedStates & CP, SCP & $7-1$ - years old \\
Marsh, 2009 & India & CP, CLP & NA \\
Migueletal., 2004 & Brazil & SCP, SCLP & $6-46$ years old \\
Nagarajanetal., 2009 & India & CLP, CP & NA \\
Penido etal., 2007 & Brazil & CP & 8 -34 years old \\
Qui Chen etal., 20I I & UnitedStates & SCP, CP & I-34 years old \\
Camargo etal., 200 I & Brazil & NA & $6-76$ years old \\
ShprintzenandMarrinan, 2009 & UnitedStates & NA & NA \\
Shyammohanetal., 20 I0 & India & NA & NA \\
\hline
\end{tabular}

Source: The authors

CLP = cleft lip and palate

$\mathrm{CP}=$ cleft palate

$\mathrm{SCP}=$ submucuous cleft palate

SCLP $=$ submucous cleft lip and palate

$\mathrm{NA}=$ not available

Table 2. Tools used in the study.

\begin{tabular}{|c|c|c|c|}
\hline Authors & $\begin{array}{l}\text { Directinstrumental } \\
\text { assessment }\end{array}$ & $\begin{array}{l}\text { Indirectinstrumental } \\
\text { assessment }\end{array}$ & Clinicalevaluation \\
\hline Araújo Netto \& Cervantes, 20 | I & videonasoendoscopy & Notused & Auditory-perceptualassessmentl \\
\hline Trindade etal., 2004 & Notused & Notused & Auditory-perceptualassessment \\
\hline Chanchareonsooketal., 2007 & nasoendoscopy & nasometry & Auditory-perceptualassessment \\
\hline Kao et al., 2008 & nasoendoscopy & Notused & Auditory-perceptualassessment \\
\hline Marsh, 2009 & videonasoendoscopy & Notused & Auditory-perceptualassessment \\
\hline Migueletal., 2004 & videonasoendoscopy & nasometry/PERCI-SARS & Auditory-perceptualassessment \\
\hline Nagarajan etal., 2009 & $\begin{array}{l}\text { Videonasoendoscopyand } \\
\text { videofluoroscopy }\end{array}$ & nasometry & Auditory-perceptual assessment \\
\hline Penido etal., 2007 & nasopharyngoscopy & Notused & Nasalair emissiontest \\
\hline Qui Chen etal., 20 I I & $\begin{array}{l}\text { lateralcephalogramof } \\
\text { nasopharyngographyand } \\
\text { nasopharyngealfiberscope }\end{array}$ & Notused & Auditory-perceptualassessment \\
\hline Camargo etal, 200 I & nasoendoscopy & Notused & $\begin{array}{l}\text { Auditory-perceptual assessment } \\
\text { focused on nasal air emission }\end{array}$ \\
\hline Shprintzene Marrinan, 2009 & NasopharyngoscopyandMRI & nasometry & Notused \\
\hline Shyammohan etal, 2010 & Notused & Notused & Auditory-perceptualassessment \\
\hline
\end{tabular}

Source: The authors.

Detailed descriptions of both types of assessment and the parameters used for the analysis of the results of these 12 studies are shown in Table 2 . The direct instrumental assessments used in these studies included videofluoroscopy, magnetic resonance imaging (MRI), nasopharyngeal fibroscopy, videonasoendoscopy, nasopharyngoscopy, and nasoendoscopy. Despite the different terms used, the last 4 assessments consisted of the same type of test performed with the purpose of viewing the velopharyngeal mechanism. The indirect instrumental assessments mentioned in these studies were nasometry and the PERCI-SARS system. The methods of clinical evaluation used in most studies were auditory-perceptual assessments and nasal airflow measurements. Such tests were analyzed according to the specific protocols of each institution. The analysis parameters for each type of instrumental assessment and auditory-perceptual assessment differed for each study (Table 2).

Our decision to conduct a systematic review with the previously mentioned objective was prompted by a problem faced by health professionals who provide clinical care to patients with cleft lip and palate, that is, the impact of VPD on these patients' verbal communication skills. 
Discrepancies in findings relating to speech nasality and the degree of velopharyngeal closure are common in clinical practice. Clinical reports of verbal communication based on auditory-perceptual assessments reveal situations where the examiners detect severe hypernasality and, conversely, videonasoendoscopy shows a small velopharyngeal gap. Inversely proportional situations also occur when a large gap has little impact on nasality. Thus, the association between the clinical and instrumental evaluations is very important for achieving a clinical conclusion as to the real condition of the velopharyngeal mechanism. Even though we are aware that the pathophysiology of the velopharyngeal sphincter is complex and involves a variety of biases produced by the patient or the examiner, we searched for studies addressing this issue (i.e., the association between the size of the gap and the impact on nasality) in a straightforward manner. Therefore, the 3 studies selected are discussed further in an attempt to determine significant aspects related to the velopharyngeal mechanism and nasality. It is noteworthy that the specific association of interest in the present review was not explained by any of these studies, revealing the scarcity of scientific literature on the topic (Figure 1).

While investigating this topic, Marsh (2009) addressed the velopharyngeal closure and provided a description of videonasoendoscopy and auditory-perceptual assessment in a study involving patients with cleft palate. Marsh suggested a classification of the residual gap in the VPS closure using different closure patterns during speech production, and considers investigation of the VPS closure pattern and analysis of lateral pharyngeal wall movement essential for establishing the diagnosis of VPD. Although there is no direct association between findings of nasality, audible nasal air emission, and the classification proposed, analysis of these findings does facilitate clinical surgical intervention.

Qi Chen et al. (2011) used analysis of the lateral pharyngeal wall movement as a diagnostic criterion for VPS, considering that most patients without nasality and audible nasal air emission have sagittal closure. This study included 276 individuals aged 6 to 12 years. Despite considering factors such as surgical age and technique, Qi Chen et al. and Marsh both highlight the role played by lateral wall movement in satisfactory functioning of the VPS, and the consequences and impact on nasality.

With the purpose of demonstrating an association between audible nasal air emission and VPS closure pattern shown by videonasoendoscopy, Penido et al. (2007) found a valid association between these aspects by means of comparison. These authors described the reliability of the correlation between the Glatzel mirror test using nasal air escape and VPS closure pattern in 21 individuals with cleft lip and palate whose mean age was 17 years. Based on

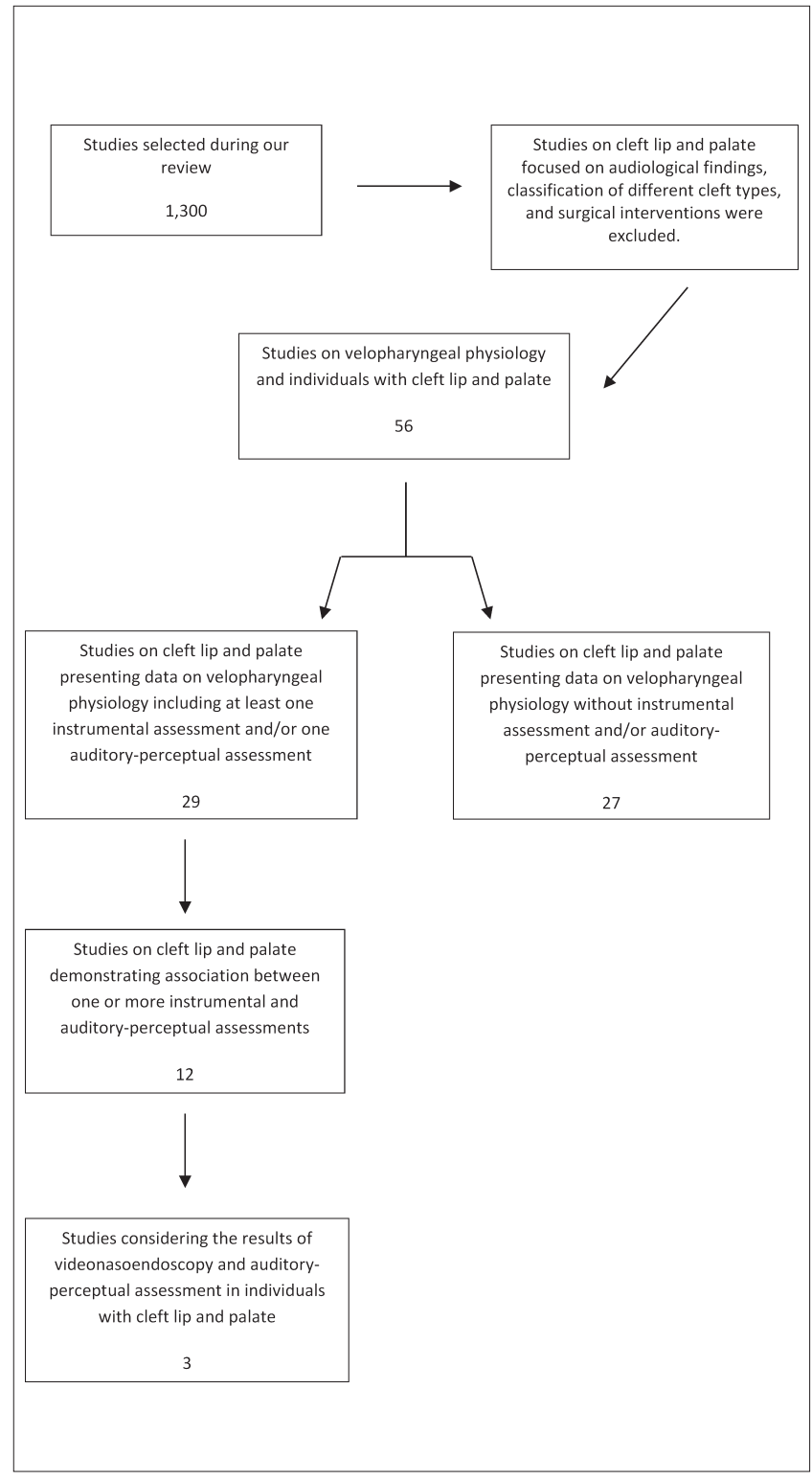

Figure 1. Logistics associated with the systematic review.

videonasoendoscopy, the size of the gap was categorized as small, medium, or large. This study demonstrated that the nasal air emission test is useful for evaluating the function of the velopharyngeal mechanism, and for establishing a direct relationship between the size of the gap and the area of condensation on the mirror. It is worth noting that these authors found divergent behaviors of the velopharyngeal mechanism considering the nasal air escape expected in an individual from this sample.

\section{CONCLUSIONS}

In the present systematic review of the literature we identified different evaluation methods used for determining 
velopharyngeal function. However, we found few studies that showed both the detailed criteria chosen to analyze the results of the assessments and the association between videonasoendoscopy results and auditory-perceptual assessments. Only 1 study demonstrated an association between findings of VPD assessed using videonasoendoscopy and the severity of audible nasal air escape evaluated by auditory-perceptual assessment.

\section{REFERENCES}

1. Peterson-Falzone SJ, Hardin-Jones MA, Karnell MP. Communication disorders associated with cleft palate. In: Peterson-Falzone SJ, Hardin-Jones MA, Karnell MP, editors. Cleft Palate Speech. 3rd ed. Missouri: Mosby; 2001. p. 16299.

2. Rocha DL. Insuficiência Velofaríngea. In: Mélega JM. Cirurgia Plástica: Fundamentos e Arte-Cirurgia reparadora de Cabeça e Pescoço. Rio de Janeiro: Medsi; 2002. p. 17896.

3. Golding-Kushner KJ, et al. Standartization for the reporting of nasopharyngoscopy and multiview videofluoroscopy: a report from an international working group. Cleft Palate J. 1990;27:337-48.

4. Conley SF, Gosain AK, Marks SM, Larson DL. Identification and assessment of velopharyngeal inadequacy. Am J Otolaryngol. 1997;18:38-46.

5. Shprintzen RJ. Instrumental Assessment Of Velopharyngeal Valving. In: Shprintzen RJ, Bardach J. Cleft palate speech management: A multidisciplinary approach. St. Louis: Mosby; 1995. p. 221-56.

6. Trindade IEK, Trindade Junior AS. Avaliação funcional da inadequação velofaríngea. In: Carreirão S, Lessa S, Zanini AS, editors. Tratamento das fissuras labiopalatinas. 2nd ed. Rio de Janeiro: Editora Revinter; 1996. p. 223-35.

7. Sell D, Harding A, Grunwell P. A screening assessment of cleft palate speech (Great Ormond Street Speech Assesmente). Eur J Disord Commun. 1999;29:1-15.

8. Genaro KF, Yamashita RP, Trindade IKE. Avaliação clínica e instrumental na fissura labiopalatina. In: Ferreira LP, BefiLopes DM, Limongi SCO. Tratado de Fonoaudiologia. São Paulo: Rocca; 2004. p. 456-77.

9. Laczi E, Sussman JE, Stathopoulos ET, Huber J. Perceptual evaluation of hypernasality compared to HONC measures: The role of experience. Cleft Palate Craniofac J. 2005;42:20210.
10. Pontes PAL, Behlau MS. Nasolaringoscopia. In: Altmann EBC. Fissuras labiopalatinas. 4th ed. Carapicuíba: Pró-fono; 2005. p. $175-83$.

11. Kuehn DP, Henne LJ. Speech Evaluation and Treatment for Patients With Cleft Palate. Am J Speech Lang Pathol. 2003;12:103-9.

12. Shprintzen RJ. Nasopharyngoscopy. In: Bzoch KR, editors. Communicative Disorders Related To Cleft Lip And Palate. 5th ed. Boston: Little \& Brown; 2004.

13. Williams WN, Heningsson G, Pegoraro-Krook MI. Radiographic assessment of Velopharyngeal function for speech. In: Bzoch KR, editor. Communicative disorders related to cleft lip and palate. 5th ed. Boston: Little \& Brown; 2004 .

14. Klassen AF, Tsangaris E, Forrest CR, Wong KWY, Pusic AL, Cano SJ, et al. Quality of life of children treated for cleft lip and/or palate: A systematic review. J Plast Reconstr Aesthet Surg. 2012;65:547-57.

15. Sampaio RF, Mancini MC. Estudos De Revisão Sistemática: Um Guia Para Síntese Criteriosa Da Evidência Científica. Rev. Bras. Fisioter. 2007;11:83-9.

16. Camargo LOS, Rodrigues MC, Avelar JA. Oclusão velofaríngea em indivíduos submetidos à nasoendoscopia na Clínica de Educação para Saúde (CEPS). Salusvita. 2001;20:35-47.

17. Chanchareonsook N, Whitehill TL, Samman N. Speech outcome and velopharyngeal function in cleft palate: comparison of Le Fort I maxillary osteotomy and distraction osteogenesis_early results. Cleft Palate Craniofac J. 2007;44:23-32.

18. Kao DS, Soltysik DA, Hyde JS, Gosain AK. Magnetic Resonance Imaging as an Aid in the Dynamic Assessment of the Velopharyngeal Mechanism in Children. Plast Reconstr Surg. 2008;122:572-7.

19. Marsh J. Velo-pharyngeal dysfunction: Evaluation and management. Indian J Plast Surg. 2009;42:129-36.

20. Miguel HC, Genaro KF, Trindade IEK. Avaliação perceptiva e instrumental da função velofaríngea na fisura de palato submucosa assintomática. Pró-Fono Revista de Atualização Científica. 2007;19:105-12.

21. Nagarajan R, Savitha VH, Subramaniyan B. Communication disorders in individuals with cleft lip and palate: An overview. Indian J Plast Surg. 2009;42:13743. 
22. Netto BCA, Cervantes O. Estudo comparativo entre pacientes fissurados portadores de insuficiência velofaríngea tratados com fonoterapia e faringoplastia. Rev. Bras. Cir. Plást. 2011;26:631-8.

23. Penido FA, Noronha RMS, Caetano KI, Jesus MSV, Di Ninno CQMS, Britto ATBO. Correlação entre os achados do teste de emissão de ar nasal e da nasofaringoscopia em pacientes com fissura labiopalatina operada. Rev Soc Bras Fonoaudiol. 2007;12:126-34.

24. Shprintzen RJ, Marrinan EMS. Velopharyngeal insufficiency: diagnosis and management. Curr Opin Otolaryngol Head Neck Surg. 2009; 17:302-7.
25. Shyammohan A, Sreenivasulu D. Speech Therapy with Obturator. J Indian Prosthodont Soc. 2010;10:197-9.

26. Trindade IEK, Genaro KF, Yamashita RP, Miguel HC, Fukushiro AP. Proposta de classificação da função velofaríngea na avaliação perceptivo-auditiva da fala. PróFono Revista de Atualização Científica. 2005;17:259-62.

27. Qi C, Qian Z, Bing S, Heng Y, Tian M, Guang-ning Z. Study of relationship between clinical factors and velopharyngeal closure in cleft palate patients. J Res Med Sci. $2011 ; 16: 945-50$. 